\title{
Global human resources or critical global citizens? An inquiry into the perspectives of Japanese university educators on global citizenship education
}

\author{
Emiliano Bosio ${ }^{1}$
}

Accepted: 17 May 2021

(C) UNESCO IBE 2021

\begin{abstract}
This article examines how Japanese university educators understand the role of Global Citizenship Education (GCE) in higher education. Data were collected by means of questionnaires and responsive interviews with 22 educators, then analyzed with the use of grounded theory and the constant comparative method. Four notions of GCE emerged from the data. The Japanese educators expressed the opinion that GCE must: (1) foster students' sense of social efficiency and economic growth; (2) enhance their English-language proficiency to prepare them for work in the global market; (3) encourage overseas experiences to support them in acquiring global consciousness; and (4) develop students' understanding of different countries. Based on the findings, the study suggests that educators' approaches to GCE in Japan are generally oriented toward neoliberal notions of GCE aimed at fostering global human resources rather than critical global citizens. In contrast, this paper concludes by proposing a critical framework informed by the values of critical pedagogy ingrained in social justice to teach GCE in Japanese universities. This approach to GCE challenges dominant neoliberal notions of the linkages between globalization and education and orients learners toward social justice.
\end{abstract}

Keywords Curriculum · Globalization · Global citizen · Higher education · Japan · Neoliberalism · Social justice

\section{Introduction}

Globalization has had the effect of expanding the scope of citizenship education beyond traditional national boundaries, calling upon worldwide educators to undertake new efforts to equip learners for today's complex societies (Bosio 2021a; Giroux and Bosio 2021). In this context, over the past 20 years, there has been a growing interest in Global Citizenship

Emiliano Bosio

bosio@toyo.jp

1 Department of English and American Literature, Faculty of Letters, Toyo University, 5

Chome-28-20 Hakusan, Bunkyo City, Tokyo 112-0001, Japan 
Education (GCE) as a means of supporting learners in developing their understanding of multiple global, national, and local issues (Bosio and Torres 2019). The development of GCE has been progressing through academic debate with theoretical orientations ranging from neoliberal to critical (Bosio 2019, 2021b; Torres and Bosio 2020a, b; Pashby et al. 2020; Bourn 2020).

One of the most frequently adopted definitions of GCE is UNESCO's (2015, p. 15): GCE is concerned with developing "the knowledge, skills, values and attitudes that learners need to be able to contribute to a more inclusive, just and peaceful world". The last two decades have seen a number of countries starting to implement GCE in both schools and universities with the intention of producing more globally oriented students [See Ho (2018), for Japan; Moon and Koo (2011), for South Korea; O'Connor and Faas (2012), for England/France/Ireland; Rapoport (2010), for the United States; Schweiswurth (2006), for Canada; Tarozzi and Inguaggiato (2018), for Italy/Austria/Ireland/Czech Republic]. These initiatives have numerous manifestations and may be implemented via formal national policies (Bamber et al. 2016) or various local initiatives (Gaudelli 2016) or introduced by a single academic (Goren and Yemini 2017). This has led several Japanese higher education institutions (HEIs) (e.g., University of Tokyo, Sophia University, and Waseda University) to include terms like global education, global citizenship, and global citizen either in their mission statements or specific programs and module outlines. Yet, while Japanese universities have marketed themselves as beacons for fostering global citizens, there has been relatively little coverage on how educators in Japan perceive GCE and implement it into curricula and classroom practices.

To fill in the gap, this qualitative study surveyed a group of Japanese educators $(n=22)$ and asked them to describe how they understand the role of GCE in higher education (HE). I selected these educators on the grounds of their substantive involvement in GCE programs/modules at both the undergraduate and graduate level. Through their responses, I identified four notions of GCE. The Japanese educators expressed the opinion that GCE must (1) foster students' sense of social efficiency and economic growth, (2) enhance students' English-language proficiency to prepare them for work in the global market, (3) encourage overseas experiences to support students in acquiring global consciousness, and (4) develop students' understanding of different countries and cultures. Based on these findings, I suggest that educators' approaches to GCE in Japan are generally oriented toward neoliberal notions. In contrast, I propose a critical framework informed by the values of critical pedagogy ingrained in social justice to teach GCE in Japanese universities. This is an approach to GCE that challenges dominant neoliberal notions of the linkage between globalization and education, orients learners toward notions of social justice, world-peace, and killing-free societies (Bosio 2017) and potentially equips them to respond to the complex local and global challenges that our societies currently face (e.g., Covid-19).

\section{Education policy in Japan: Development of global human resources}

In the last decade, the Japanese government has put policies in place for the recruitment of overseas talent, encouraged students to undertake studies overseas, and internationalized the country's top universities (Kim 2016). These initiatives in Japan are referred to as gurobaru jinzai ikusei (development of global human resources), and they have the cross-party support of a globalist coalition. This coalition incorporates all of the most conservative influencers in Japanese educational policy, including MEXT (Ministry of Education), the LDP (Liberal Democratic Party) cabinet, Keizai Doyukai (Japan Association 
of Corporate Executives), and the Keidanren (Japan Business Federation). It is unusual to find that both METI (Ministry of Economy, Trade, and Industry), previously a bureaucratic rival of MEXT, and the DPJ (Democratic Party of Japan) are also part of this globalist coalition.

This grouping has made a commitment to the ambitious target of doubling the numbers of Japanese students undertaking studies abroad by 2020, increasing the numbers of Japanese universities that can compete globally by $100 \%$, and overseeing improvements in English-language results for Japanese students. To achieve this, they have made a ¥6.9 billion annual investment in scholarships for overseas study for Japanese nationals. Funding to allow high school and university students to experience overseas study was doubled in 2014 (¥222 million per year). Three programs (Global 30, 2009-2014; Super Global, 2014-2023; and Promotion of Global Human Resource Development, 2012 have injected over $¥ 7$ billion per year for funding a more "globalized” curriculum and staff. This includes more than 150 new English-language courses (Nitta 2019).

\section{Global citizenship education in Japan}

Guidelines for the Japanese HE curricula published in the last 10 years stressed the requirements for students to develop global perspectives by understanding global issues, having more understanding and greater respect for alternative races and cultures, and enhancing English-language abilities. This new initiative emphasized the importance of international perspectives, universal human rights, global citizenship, and global interdependence rather than the more traditional themes of Japanese education regarding students' rights and obligations as Japanese citizens and the promotion of patriotism (Yonezawa 2017).

At present, many websites for major Japanese HEIs refer to the need for greater integration internationally and the presence of the global community. Many institutions provide programs linked to GCE and administrators, and educator staff are very welcoming to the concept of establishing global connections. Tokyo's Sophia University provides both an $\mathrm{MA}$ and $\mathrm{PhD}$ course in Global Studies that examines "world systems, transnational processes, and global-local interactions from perspectives of anthropology, history, political science, religious studies and sociology" (Sophia University 2021). International Christian University allows students to take a major in Global Studies that intends "to educate responsible, global citizens who can identify significant world issues, examine the structure and related phenomena of global governance using an interdisciplinary approach, and exercise leadership and create partnerships to promote conflict resolution in the global community of the 21 st century" (International Christian University 2021). The University of Tokyo (U-Tokyo) puts forward the Global Leadership Education Program (GLP), a transdisciplinary, 4-year undergraduate program "designed to equip talented UTokyo students with the global competencies and skills necessary to act effectively as creative, knowledgeable, and responsible players and 'change-makers' on the global stage" (University of Tokyo 2021).

As mentioned above, it is evident that Japanese universities are now attempting to introduce GCE/international elements into their curricula to provide their students with enhanced global skills, to use culturally mixed learning environments to promote links between cultures, and ultimately to create graduates who are comfortable as part of the globalized world. In a break with the past, the universities are moving away from rhetorical mission statements and offering their students a new form of education. However, there are still contradictions in Japanese educational policy in that the emphasis remains on 
providing students with the global competencies and skills to make them competitive in the world market rather than aiming to prepare students to live respectfully with other cultures.

Ultimately, the new initiatives seem aimed more at working with "market democracy", than "moral democracy" (Dill 2012). Market democracy in Japan integrates the global community in relation to market rationality, and students are encouraged to equip themselves with certain global competencies and skills, such as English-language proficiency and study-abroad experiences, mostly in the Global North, to compete in the globalized market, and to be well prepared for their "career-destinations". Thus, developing a postneoliberal curriculum in Japan is very much a work in progress. It is not yet obvious whether Japanese universities and their educators are fostering global human resources who can fit straight into the international job market or global citizens who will have the critical knowledge and values gained through their education to create and inhabit peaceful and sustainable communities.

\section{Theoretical dimensions of GCE}

GCE theoretical approaches help educators to uncover what kind of global citizens they aim to produce and what implications these approaches may have in terms of cognitive, social-emotional, and behavioral curriculum objectives. I frame the conversation on GCE in Japan using three approaches to university teaching: neoliberal, Anglo-centric, and critical. This organization allows me to be better equipped for analysis of the research data.

\section{Neoliberal approaches to GCE}

Neoliberal approaches to GCE stress the need to develop skills and knowledge in order to successfully compete in the global market; this GCE-type can be described as an instrumentalist orientation because it has associations with human capital theory, in which education is first and foremost a way of making the individual competent to succeed economically (Giroux 2020). The chief purpose of GCE from a market-based economic standpoint is "equipping students with the skills needed for a global economy such as the learning of economically useful languages" (Marshall 2011, p. 8). From a neoliberal GCE standpoint, a global citizen is one who is an effective participant in the liberal economy dominated by capitalism and technology.

Neoliberal perspectives often influence the ways in which GCE is practiced. Marshall (2011) offers the example of GCE in the Netherlands, where it is seen by some upper-middle-class parents as a way to equip students with the attitudes, skills, and knowledge they will need in the global marketplace. The influence of market-based economic theory in GCE can also be seen in the way it is taught. Camicia and Franklin (2011) demonstrate the ways in which the concept of market economy has become integral to curriculum reform in the United Kingdom and the Philippines. For example, in the Philippines, being able to speak English is regarded as a central skill of competent global citizens who wish to work in the global market. Curriculum reform documents in the Philippines describe global citizens as being "empowered through a world market and also given access to English-speaking journals, journals that increase the presence of Filipina/o scholars in global academic settings" (Camicia and Franklin 2011, p. 316). 


\section{Anglo-centric approaches to GCE}

While knowledge of more than one language is a significant aspect of GCE and enables the creation of spaces for dialog and multicultural understanding despite linguistic boundaries, an Anglo-centric GCE can have unfavorable consequences, such as contributing to mounting global economic disparities, limiting communication among diverse linguistic groups, and contributing to the extinction of other languages. In fact, the hegemony of English or "Anglo-centricity" in GCE can be framed in terms of cultural imperialism, "a form of soft imperialism which imposes "Western" ways of thinking, doing, and acting" on other civilizations (Marginson 1999, p. 19), and specifically, linguistic-imperialism which uses global English as a key dimension of the United States' empire. Marginson (1999) also suggests that the power of English as a symbolic system in the global linguistic market is such that its legitimacy tends to be uncritically accepted.

The problem is that when GCE is dominated exclusively by Anglo-centric and neoliberal approaches, it will generally be employed as a labor market strategy and not a way of encouraging critical thought or active social engagement for reform. Thus, Anglo-centric/ neoliberal concepts of GCE must be confronted if, in the future, we are to produce citizens who recognize their rights and responsibilities with regard to driving progress for themselves and their societies. Yet, given their "dominance" in HE, it can be complex to pose alternative positions of GCE more oriented toward critical pedagogy. In such a pedagogy, academics may seek to go beyond fostering the global worker-a performative student type who is an entrepreneur always looking out for the best prospects-while critically engaging with neoliberal GCE.

\section{Critical approaches to GCE}

A growing number of scholars, including the author of this study, have discussed and attempted to conceptualize discursive perspectives that challenge narrow, market-based, and classically Western-centric neoliberal conceptions of GCE to call for more critical stances (embracing, for instance, decolonial and environmental perspectives) (Bosio 2020, 2021c, Pashby et al. 2020; Dorio 2017). Therefore, theoretically, I situate this study within a critical position of GCE grounded in the values and knowledge of critical pedagogy and social justice. One of the aims of a critical GCE is to assist learners in reflecting critically on context and their opinions and to assist them in being part of the creation of a new future with its roots in social justice and sustainability. In this view, GCE becomes more than service delivery because it should be a means of "conscientization", a concept that refers to achieving an in-depth and critical understanding of the world-allowing for the perception and exposure of social and political contradictions-and identity development through the transmission of knowledge and values across generations (Freire 2018). The notion of a GCE conceptualized in this perspective could also represent a potential distinct pedagogical framework to reimagine citizenship education in a more critical and ethical perspective that has its foundation in critical theories as discussed by Freire and Macedo (1995), Giroux (2020) and Mignolo (2000a, b). This also encompasses (a) decolonial value-elements, (b) notions of critical ethics, and (c) eco-critical views (Andreotti 2015; Torres 2017; Lupinacci 2017), as I will discuss in more detail in the next section. 


\section{De-colonialism}

From a critical perspective, Andreotti (2011) distinguishes educators' approaches to GCE from the "soft" liberal approach, proposing "decoloniality and diversity" rather than "neutral universal subjectivities" (Andreotti 2011, p. 395). The decolonial approach to GCE encompasses educators' focus on the ways in which knowledge production functions, on developing hyper-self-reflexivity, a pedagogical focus on dissensus that would assist learners in dealing with complexity and paradox, and an attempt to move GCE discourses further than simply "ethnocentrism and absolute relativism" (Andreotti 2011, p. 395). Such approaches to critical literacy by academics (Andreotti 2006, p. 49) could enable them to function "as cultural agents" in a negotiation between a variety of viewpoints (Andreotti 2011, p. 395) to prevent the reproduction of stereotypes that could be harmful to students. Critical and postcolonial theory demonstrate that uncritical discussion related to neoliberalism, globalization, and internationalization may help to support inequalities in terms of colonial relations.

This sort of value-orientation suggests that conceptualizing a critical GCE means also paying "attention to the false universalism of globalisation and shows how contemporary social, political, economic, and cultural practices continue to be located within the processes of cultural domination through the imposition of imperial structures of power" (Rizvi 2007, p. 256). These perspectives imply that through a critical GCE, academics attempt to rectify injustice, exploitation, and inequality that is inflicted on former colonies through (neo-)colonization and to be disruptive to "the persistent 'neo-colonial' relations within the 'new' world order..." (Bhabha 1994, p. 6). Academics employing this approach "attempt to shift the dominant ways in which the relations between Western and non-Western people and their worlds are viewed" (Young 2003, p. 2).

\section{Caring ethics}

Educators' approaches to critical GCE are also founded in caring and compassionate ethics and attempts to comprehend, analyze, and find a resolution for the contemporary crises of migration. Questions of human rights for immigrants remain contentious. For example, the work of Torres (2017) suggests that educators employing a critical GCE are responsible for promoting St. Ignacio's concept of cura personalis (caring ethics). Caring for individuals and human rights is a foundational pillar of critical GCE; this also incorporates central concepts of feminist theory. From this perspective, critical GCE can be located inside a framework for educational social justice. This approach expands beyond simple cognitive learning and numbers-based technocratic thought. It represents a pursuit of holistic education encompassing outcomes that include spirituality, art, aesthetics, and ethics, as well as ambitions toward the creation of peace in line with the UNESCO commission report of Jacques Delors, Learning: The Treasure Within. Delors emphasizes the importance of living in harmony with one another and the rest of the planet. Finally, critical GCE advances learning methodologies that strongly emphasize collectivized ethics of knowledge in an era where we are increasingly at the mercy of individualized modules, possessive competitive individualism, and self-directed learning concepts that are favored by neoliberals, as Mayo (2019) explains. 


\section{Eco-critical perspective}

Eco-critical educational frameworks may be defined as a means of examining and analyzing cultural and linguistic elements, with their associated beliefs and values, that helped to mold human thought and so perpetuate injustice, along with the capability of confronting assumptions that support unjustified suffering in society and the degradation of the environment (Lupinacci and Happel-Parkins 2015, 2016a, b). This approach suggests that academics focus on values related to diversity and the structural ecosocial correlations that exist educationally, culturally, and linguistically and control the ways in which we acknowledge and comprehend differences. Lupinacci and othersfor example, Weintraub et al. (2006)—introduce the term eco-tistical to compensate for the absence of an English-language term describing "humans relating to the nonhuman environment in a harmonious, respectful, and pragmatic manner" (p. 55). By swapping out ego- for eco-, they move the "focus away from self and toward home or habitat" (Weintraub et al. 2006, p. 55) to make up for the lack of an antonym for anthropocentric (revolving around humans) and egocentric (revolving around the self). In this context, eco-centrism describes the ecological consciousness that Martusewicz and Edmondson (2005) define as being an "eco-ethical consciousness" (p. 73), one that considers the environmental and social impacts of decisions and acknowledges that they are effectively indivisible.

Framing the discussion around GCE into a growing corpus of scholarship related to eco-critical, eco-ethical, or eco-tistical values is to acknowledge that human beings in both Western and Eastern industrial culture, by virtue of situating themselves as a superior species in isolation from all other beings on Earth, animate and inanimate, are limited in their understanding (Lupinacci and Happel-Parkins 2016b). Abram (1999) refers to the notion of more-than-human to delineate the more substantial ecological relationships that prevail on Earth outside of those systems that examine only human/ human relationships. The more-than-human terminology is also central to this discussion of GCE because it encompasses rocks, soil, forests, streams, animals, and plants to make the point that the notion of "interconnectedness" goes beyond human beings and comprises all living beings. A discussion supported by Misiaszek (2015) advocates for an eco-pedagogy of GCE oriented toward fostering consciousness of the intertwined human-environment relationships that demand an amalgamation of education for/ through social and ecological justice.

\section{Methodology}

I conducted this qualitative study to examine the views of Japanese educators $(n=22)$ on GCE. I employed a non-probabilistic, intentional sample consisting of HE Japanese educators working for six top universities (three public and three private). While I recognize that there may be more universities offering undergraduate and graduate GCE programs in Japan, the six selected represent the diversity of most existing programs and provide a context for this investigation. The core benchmark for choosing these six universities was the presence of educators teaching programs that focus on GCE. The educators participated voluntarily in the inquiry. Fifteen were women and seven were men. They all had more than 7 years of teaching experience in Japanese HE. Two of 


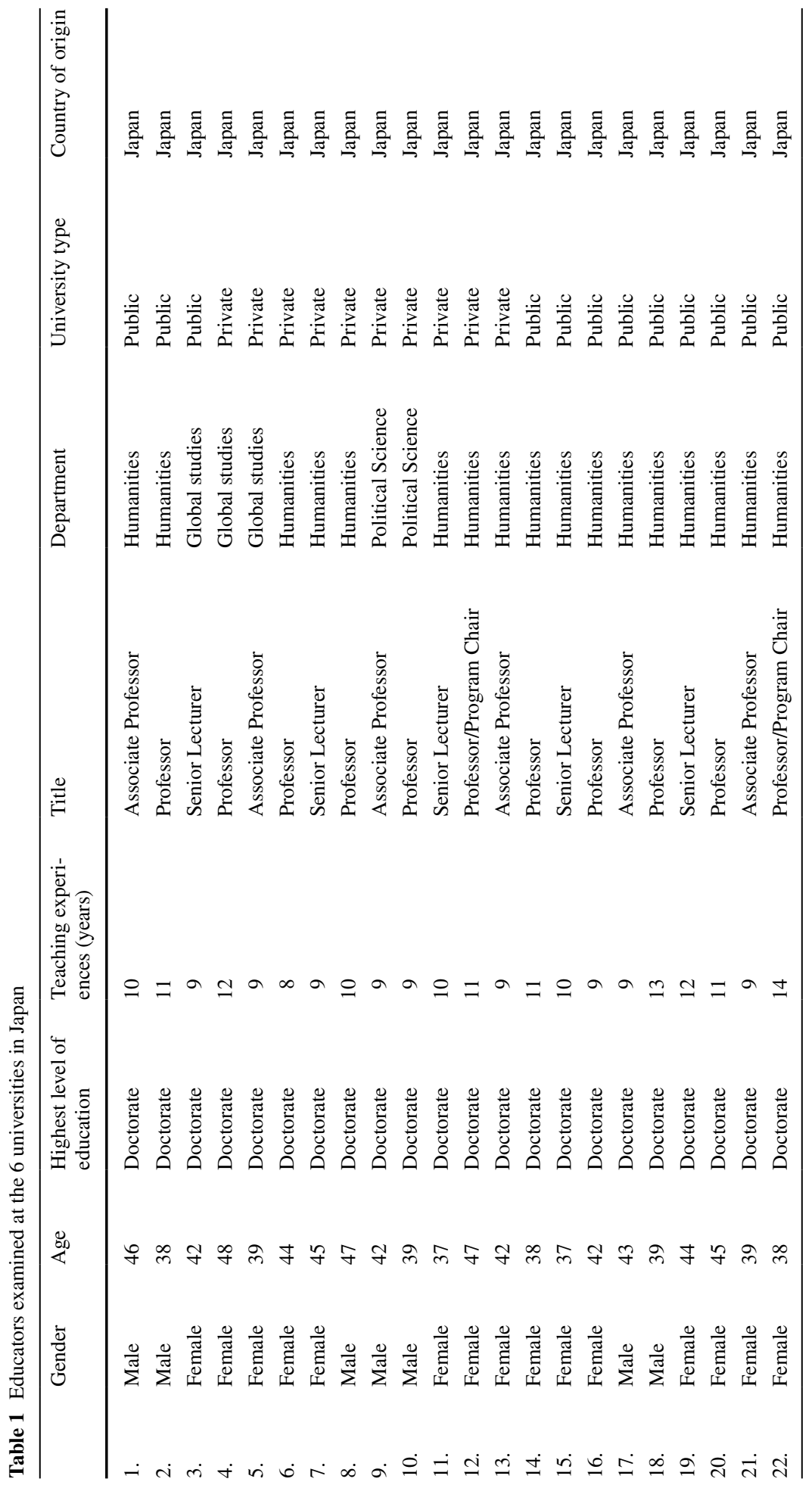


them had also been program chairs. They all held doctoral degrees. For the purposes of confidentiality, I assigned code numbers to participants. For example, I used JP1 to identify academics in the text (where JP = Japan and each number identifies an academic (See Table 1).

I collected data for the study in two stages. In the first stage, I asked the participants to respond to a 15-item questionnaire they received by electronic mail. The purpose of the questionnaire was to situate the topic among the participants and collect background information and opinions on GCE. Examples of questions included: Can you describe in detail your GCE program and introduce reasons why you endorse the teaching of GCE? What themes of GCE are promoted in your program? What are the core expectations of your GCE program?

In the second stage of the study, I asked the educators to participate in a responsive interview (Rubin and Rubin 2005). A responsive interview is a conversational partnership between researcher and participant. This allowed me to understand the experiences of the participants by following up, deeply and extensively, on the interviewee's comments. Examples of questions included: What knowledge and values do you aim to develop through GCE? Why? Are there specific areas of knowledge and specific values on which you particularly focus? If so, why? Why is GCE necessary? Who is GCE targeted at, and what are the reasons behind this setting? The interviews lasted an average of $45 \mathrm{~min}$. The questionnaires and responsive interviews were conducted in English. Originally, the participants were given a choice to use either English or Japanese. However, all participants preferred to express their ideas in English because they believed this language would be immediately understandable to me rather than being mediated through what they defined as a "time-consuming" translation process. All participants teach and publish in English, and they had spent a significant amount of time in English-speaking countries either to complete their PhDs/MAs and/or to advance their academic research. Therefore, their Englishlanguage competency was not an issue.

To analyze the data, I used grounded theory methodology, first developed by Glaser and Strauss (1967). The grounded theory provides a key method for data analysis and theory construction in qualitative research. This method enabled me to describe a participant's point of view with regard to GCE while concomitantly aiming toward an interpretive dimension, which comprises the core of my content analysis. I identified segments of educators' perspectives on GCE and then arranged preliminary and overlapping themes using the constant comparison method (CCM), which "combines systematic data collection, coding, and analysis with theoretical sampling in order to generate theory that is integrated, close to the data, and expressed in a form clear enough for further testing" (Conrad et al. 1993, p. 280). CCM integrates four stages: “(1) comparing incidents applicable to each category, (2) integrating categories and their properties, (3) delimiting the theory, and (4) writing the theory" (Glaser 1965, p. 439). This process revealed pertinent information and passages, which I organized, connecting data to themes or categories (Merriam and Grenier 2019). The findings below are presented within themes that were coded from the data. To support and explain each theme, I used direct quotes from educators.

\section{Results}

The following results reveal Japanese educators' accounts of GCE in relation to how they perceive its role in HE. I begin by discussing the first theme: GCE must foster students' sense of social efficiency and economic growth. Then, I address the second and third 
themes: GCE must enhance students' English-language proficiency to prepare them for work in the global market, and GCE must encourage overseas experiences to support students in acquiring global consciousness. Lastly, I describe the fourth and last theme: GCE must develop students' understanding of different countries and cultures.

\section{Theme 1: GCE must foster students' sense of social efficiency and economic growth}

In this section I discuss the first theme that emerged from the Japanese educators' perceptions of the role of GCE in HE. This study found that the Japanese educators operate in a context of educational reforms dominated by neoliberal values that have been enacted by the Japanese Ministry of Education (MEXT) over the past 20 years. Such reforms influence directly and indirectly how educators in Japanese universities understand and practice GCE. They center around the need to provide students with the values they need to achieve social efficiency. The Japanese educators confirmed that, throughout Japan, a significant element of what is perceived to represent educational reform can be linked to the neoliberal principle that it is possible to achieve economic and social progress only through educational approaches that focus on meeting the needs of the international marketplace.

Not surprisingly, the study found that a central theme that underpins GCE in HE according to the Japanese educators is the need to nurture students as global human resources who focus on economic growth, a notion that one of the Japanese educators referred to as fostering "the indulgent global citizen" (Educator, JP1). An indulgent global citizen is an individual who has an express aspiration to learn English as a second language, travel extensively, and secure a role in a major international corporation. Yet, he or she does not show an interest in being actively engaged in sustainable activities (e.g., setting up recycling stations around campus, organizing a donation program during moving season, visiting sustainability summits, hosting a sustainability fair, touring renewable energy plants) or an interest in critical values (e.g., justice, fairness, equity). These students are often more interested in how GCE can further their careers and outlooks.

In relation to this, it is interesting to note that three additional themes were repeatedly emphasized by the Japanese educators. These include: (a) GCE must enhance students' English-language proficiency to prepare them for work in the global market; (b) GCE must include opportunities for students to gain overseas experience to extend their global consciousness, and (c) GCE must develop students' understanding of different countries and cultures. I discuss these three themes in the next sections.

\section{Theme 2: GCE must enhance students' English-language proficiency to prepare them for work in the global market}

In this section I discuss the second theme that emerged from the Japanese educators' perceptions of the role of GCE in HE. The investigation found that the Japanese educators described GCE as a pedagogical instrument through which they can teach their students the importance of learning a foreign language and the ability to converse in multiple languages. This is deemed "to be imperative to establishing a competitive foothold in the international market" (Educator JP2). The emphasis these educators give to learning English as a second language (ESL) in Japan positions their views of GCE as a combination of an economic and personal pursuit. For instance, Educator JP3 described how the students 
he taught were able to speak "good English," were "employable global citizens," and he was "confident that they will get an excellent job in some Japanese global corporation".

When talking about students' job prospects on the global market, Educator JP4 highlighted how: "Japanese companies are looking for employees who have the right qualifications, talent, intelligence, and confidence to compete on the global market, and they aren't really bothered whether you are a global citizen. Clearly, it is applicants who have the qualities mentioned who can speak fluent English who usually get the job". Educator JP5, who has been lecturing in Japan for more than 10 years, expanded: "Being able to communicate in English is central to the corporate world of Japan. Japanese companies recognize that they need to hire global citizens, which makes good English skills a priority. This in turn has massively increased the demand for high-quality English educators in Japanese universities".

One potential explanation for Japanese educators' focus on teaching Japanese students English-language skills in GCE is that global corporations have increasingly played an active role in Japanese universities' efforts to internationalize. Furthermore, the corporate world as a whole has exhibited a major movement toward English as the primary language of business. This perspective was highlighted by Educator JP6, who pointed out that "English is effectively the lingua franca of the globalized environment, being the best language for accessing employment opportunities, higher education, and information in general, and it is the central means of communication in both business and diplomacy. English is also the main language for communication between those in the science and technology worlds".

In this regard, Japanese educators believed that students need to acquire English-language skills to meet the needs of the global market. This may be problematic in that the focus on English can bestow native-English-language-speaking countries with a degree of superiority that serves to extend global inequality. Yet within the Japanese context, there seems to be a simple perception among educators of the demands of the rest of the world as a whole that fails to take into consideration what Educator JP7, in contrast with other Japanese educators, critically referred to as "the very local impact of language policies on access to economic resources, to policy-making institutions, and to political power".

The discourse around transforming English-language use and language education into commodities for a global marketplace takes a particular stance with regard to what Educator JP8 calls "the cultural, political, social, and economic implications of language programs". For instance, Educator JP8 described how this market-oriented perspective appears to be "unconcerned with the role English might play in perpetuating global inequalities, as well as globalization's tendencies for homogenizing cultural traditions". Overall, it appeared that the need for Japanese students to learn the English language has become entrenched in contemporary educational priorities and has become inextricably linked with Japanese educators' perspectives of what it means for Japanese students to evolve into global citizens who possess the skills to obtain a competitive position in the global market.

\section{Theme 3: GCE must encourage overseas experiences to support students in acquiring global consciousness}

In this section, I discuss the third theme that emerged from the Japanese educators' perceptions of the role of GCE in HE. The study revealed that the Japanese educators consistently stressed the need for students to travel to acquire a global perspective. Yet, it appeared that the emphasis on "global" was reflective of the Japanese participants' perspectives that the 
values and knowledge that students require to operate effectively on the international market cannot be accessed through classroom learning experiences alone. This perspective was embodied in the view shared by Educator JP9: "Through the study of foreign culture and language and spending time abroad living and working, Japanese students understand better the many touchstones between cultures and also develop a respect for difference, which establishes an excellent framework for global citizenship and helps them with their career prospects". In closing, and somewhat surprisingly, a portion of Japanese educators $(n=7)$ suggested that simply living abroad or studying abroad are not always effective in developing in students a sense of global citizenry; instructional programs should be aiming for an optimum medium between these two aspects but also be firmly entrenched in the local. For example, Educator JP10 stressed this view: "Experience abroad is extremely valuable in terms of student's development, and it is also a valuable way of building a personal identity. If foreign study is combined with local worthwhile education programs, this can greatly help to develop global citizenship and nuances of both the local and the global".

\section{Theme 4: GCE must develop students' understanding of different countries and cultures}

In this section, I discuss the fourth and last theme that emerged from the Japanese educators' perceptions of the role of GCE in HE. The study established that the Japanese educators understood GCE as oriented to enhancing students' understanding of different countries and cultures and developing cooperative partnerships with different nations. However, this seemed to be conceptualized in an individualistic "soft" manner and is more linked to raising students' "soft" awareness, as opposed to encouraging students to take concrete actions. These educators did not describe GCE as a tool to actively encourage students to reflect on controversies associated with significant international issues. For example, they said that they typically avoid encouraging students to make ethical or moral judgments in relation to politics. In this regard, the primary goal of the Japanese educators was, as Educator JP11 indicates, to employ GCE as a tool for "enhancing students" general knowledge of the world and the people within it. For instance, in situations in which classroom discussions moved toward questions of moral, ethical, or political values, Japanese educators adopted a neutral position.

\section{Conclusion: Proposing a critical pedagogical framework for GCE in Japan}

The purpose of this study was to explore how a group of Japanese educators $(n=22)$ understand the role of GCE in HE. The Japanese educators expressed the opinion that GCE fosters students' sense of social efficiency and economic growth. This links to the following themes: GCE enhances students' English-language proficiency to prepare them for work in the global market, and GCE encourages overseas experiences to support students in acquiring global consciousness. The Japanese educators also believe that GCE develops students' understanding of different countries. The emergence of these themes mirrors educational reforms developed by the MEXT over the past two decades, when there has been a greater focus on making students job ready as a key goal of education. In this context, findings from this study suggest that the teaching of GCE in Japan has not yet developed a comprehensive pedagogical approach that integrates the learner and the learning context in 
relation to social inequalities affecting the global community. For example, the participants did not describe GCE as a tool to achieve critical knowledge and did not seem interested in developing decolonial value-elements, notions of critical ethics, and eco-critical views. There is instead an excessive focus by these educators on fostering excellent English speakers as global human resources (rather than critical global citizens) in the pursuit of personal and economic wealth. This locates their approaches to GCE in Japan within neoliberal and Anglo-centric paradigms, as described in my theoretical framework.

I propose that educators in Japan should place less emphasis on neoliberal/Anglo-centric approaches to GCE because it is well-documented that GCE initiatives that attempt to address global challenges without critically examining historical and systemic patterns of oppression and inequality tend to promote simplistic understandings of global problems and solutions, paternalistic North-South engagements, and ethnocentric views of justice and change (Andreotti 2015; Pashby and Andreotti 2016; Pashby et al. 2020). Therefore, I propose a GCE situated within a critical paradigm informed by critical pedagogy ingrained in social justice. A notable element of Freire's (2004) conception of critical pedagogy is that education should be politically "conscientized" by constantly being reconstructed and by being engaging, something not all academics offer. Academics who are critically conscious and committed can create spaces for dialog, criticism, and participation by supporting students in constantly rethinking and recreating their identity.

A GCE based on critical pedagogy offers encouragement for learners to have more profound and responsible interactions and exchanges with their communities, both locally and globally. Academics who implement this form of GCE assume a pedagogy supporting the questioning of injustice and underprivileged sections of society. Social justice approaches to GCE can offer a rebuttal to those who regard HE as essentially economic and instrumental, asking for efficient "evidence-based" educational outcomes. When GCE is ingrained in critical pedagogy, allowing students to be ignorant of or accepting of social injustice will not occur. It will not be acceptable to be conformist, and students will be expected to be indignant in the face of human suffering and oppression. Academics approaching GCE from a critical pedagogy perspective will help to show students that academia values risktaking, making decisions, and learning from errors and that they will be supported in their endeavors to build a more equal society.

In this view, a critical GCE (see Figure 1), as I propose it in this study, must include core elements of de-colonialist (e.g., Andreotti 2006) critical/ethical (e.g., Torres 2017) and eco-critical (e.g., Lupinacci 2017) discourses. For example, it proposes decoloniality and diversity rather than neutral universal subjectivities while allowing learners to undertake analyses of their preconception, positions, and identity as they relate to the complexities of local/global structures (de-colonialism); it promotes St Ignacio's concept of cura personalis (caring ethics) while encouraging learners to care for individuals and human rights as a foundational pillar (caring/ethics); it encourages ecological consciousness and supports learners in examining the injustice created by humanity's perception that it is the supreme being on Earth (eco-critical).

Academics who employ a critical GCE approach encourage students to examine the causes of global inequalities and poverty and thus subvert the traditional colonial reading of historical issues by looking at the politicized ahistorical use of poverty. They also support students in developing a knowledge of the inequality of justice (Andreotti 2006) and macrostructural relationships (Torres 2017); learners acknowledge and potentially are encouraged to contrast the historical view that there is only one path toward human development, the neoliberal; and that Western capitalism, knowledge, technology, and forms of government (e.g., liberal democracy) are the only truly valuable templates 


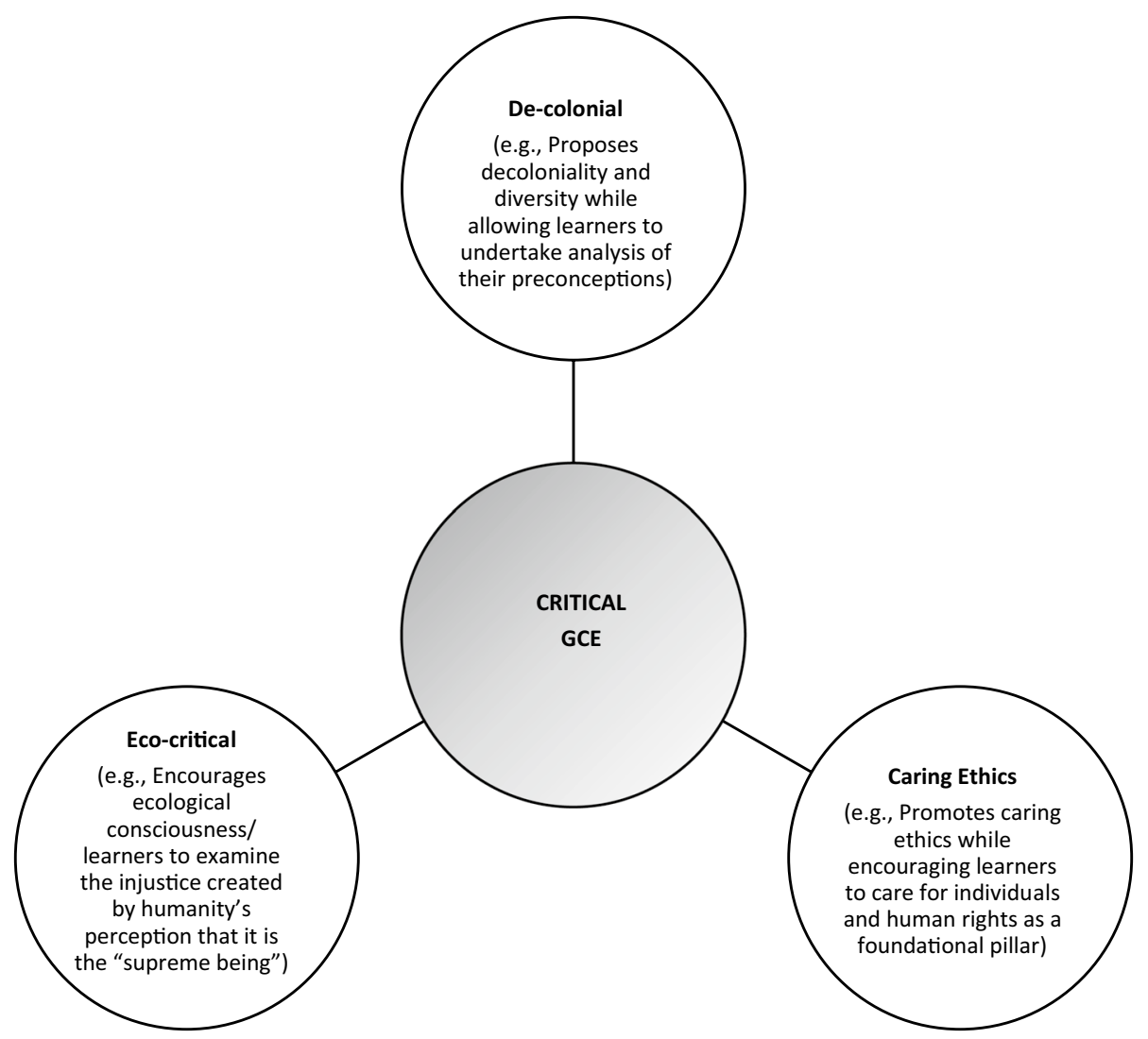

Figure 1 Elements of critical GCE

available. Academics who employ a critical GCE approach would also attempt to foster in learners the knowledge and values that would enable them to critically evaluate social, political, and economic inequalities - in other words, to understand the ways in which a neoliberal agenda is keeping the inequalities of colonialism alive. Such knowledge and values should help graduates demonstrate that the supposedly universal impacts of globalization are many and varied, and understand the ways in which present-day cultural, economic, political, and social norms are still heavily influenced by the cultural hegemony of imperial power structures.

Lastly, academics would also foster global citizens' eco-criticality. This would help them "engage in recognizing an anthropocentric worldview-that is, one that takes humans as the reference point [also defined as ego-tistical] —and how that worldview is culturally constituted and maintained" (Lupinacci 2017, p. 22). It would support them in developing a more sustainable worldview, which Lupinacci defines an eco-tistical, one that "does not explicitly perpetuate human-supremacy" (p. 21) and through which the global citizen learns to recognize ways in which the injustice, exploitation, and inequality created by human-centrism can be disrupted, based on political and ethical grounds for acting. In this view, global citizens' actions are informed by responsible and ethical values (Lupinacci 2017). This in turn, should equip critical global citizens with 
knowledge and values such as critical awareness and commitment to build a sustainable society.

To conclude, a limitation of the present study may be the relatively restricted sample size and the choice of samples exclusively from six top universities of Japan. Thus, it will be worth investigating a larger sample of Japanese educators to better understand their context-specific pedagogical approaches to GCE and how these compare with the current sample. This can be done by conducting a large-scale electronic survey in multiple Japanese regions with follow-up interviews. Yet, my proposal for a critical approach to GCE poses challenging questions for future research on GCE in Japan-for example, how to best support educators teaching GCE in Japan to re-orient their pedagogical approaches in a more critical perspective, which has its foundation in critical theories as put forward by Freire and Macedo (1995), Giroux (2020), and Mignolo (2000a, b).

As I mention somewhere else (Bosio 2019), in times like these, particularly during the Covid-19 pandemic, we need to re-think the value of GCE more than ever. We need the capacity for critical thought and analysis, and we need educators committed to creating these values. As universities in Japan (and worldwide) nurture the next generation of leaders, entrepreneurs, teachers, and volunteers who are forced to operate in the illusory world of neoliberal late capitalism, educators who populate them should develop the wisdom to perceive the interconnectedness of all human lives, the courage to attempt to appreciate people of different walks of life, and the compassion to maintain a creative empathy that extends beyond one's immediate contexts. Who knows, it might even prove to be an effective remedy to the malevolent neoliberalism that defines our epoch.

\section{References}

Abram, D. (1999). A more than human world. In A. Weston (Ed.), An invitation to environmental philosophy (pp. 17-42). Book Section, New York, NY: Oxford University Press.

Andreotti, V. (2006). Soft versus critical global citizenship education. Policy and Practice: A Development Education Review, 3, 40-51.

Andreotti, V. (2011). Actionable postcolonial theory in education. New York, NY: Palgrave Macmillan.

Andreotti, V. (2015). Global citizenship education otherwise: Pedagogical and theoretical insights. In A. A. Abdi, L. Shultz, \& T. Pillay (Eds.), Decolonizing global citizenship education (pp. 221-229). Rotterdam: SensePublishers.

Bamber, P., Bullivant, A., Glover, A., King, B., \& McCann, G. (2016). A comparative review of policy and practice for education for sustainable development/education for global citizenship (ESD/GC) in teacher education across the four nations of the UK. Management in Education, 30(3), 112-120. https://doi.org/10.1177/0892020616653179.

Bhabha, H. K. (1994). The location of culture. New York, NY: Routledge.

Bosio, E. (2017). Educating for global citizenship and fostering a nonkilling attitude. In J. Evans Pim \& S. Herrero Rico (Eds.), Nonkilling education (pp. 59-70). Honolulu: Center for Global Nonkilling.

Bosio, E. (2019). The need for a values-based university curriculum. University World News. https://www. universityworldnews.com/post.php?story $=2019092415204357$.

Bosio, E. (2020). Towards an ethical global citizenship education curriculum framework in the modern university. In D. Bourn (Ed.), Bloomsbury handbook for global education and learning (pp. 187-206). London: Bloomsbury. https://doi.org/10.5040/9781350108769.0025.

Bosio, E. (Ed.) (2021a). Conversations on global citizenship education: Perspectives on research, teaching, and learning in higher education. New York, NY: Routledge.

Bosio, E. (2021b). Global citizenship education as a meta-critical pedagogy: Concluding reflections. In E. Bosio (Ed.), Conversations on global citizenship education: Perspectives on research, teaching, and learning in higher education (pp. 185-190). New York, NY: Routledge.

Bosio, E. (2021c). Conversations with educators on global citizenship education: In the pursuit of social justice. In E. Bosio (Ed.), Conversations on global citizenship education: Perspectives on research, teaching, and learning in higher education (pp. xx-xxiv). New York, NY: Routledge. 
Bosio, E., \& Torres, C. A. (2019). Global citizenship education: An educational theory of the common good? A conversation with Carlos Alberto Torres. Policy Futures in Education, 17(6), 745-760. https://doi.org/10.1177/1478210319825517.

Bourn, D. (2020). The emergence of global education as a distinctive pedagogical field. In D. Bourn (Ed.), Bloomsbury handbook for global education and learning (p. 11). London: Bloomsbury Academic.

Camicia, S. P., \& Franklin, B. M. (2011). What type of global community and citizenship? Tangled discourses of neoliberalism and critical democracy in curriculum and its reform. Globalisation, Societies and Education, 9(3-4), 311-322. https://doi.org/10.1080/14767724.2011.605303.

Conrad, C., Neumann, A., Haworth, J. G., \& Scott, P. (Eds.) (1993). Qualitative research in higher education: Experiencing alternative perspective and approaches. Needham Heights, MA: Ginn Press.

Dill, J. S. (2012). The moral education of global citizens. Society, 49, 541-546. https://doi.org/10.1007/ s12115-012-9599-8.

Dorio, J. N. (2017). Lessons from Los Angeles: Self-study on teaching university global citizenship education to challenge authoritarian education, neoliberal globalization and nationalist populism. Journal of Global Citizenship \& Equity Education, 6(1), 1-30.

Freire, P. (2004). Pedagogia da tolerância [Pedagogy of tolerance]. São Paulo: UNESP.

Freire, P. (2018). Pedagogy of the oppressed. London: Bloomsbury.

Freire, P., \& Macedo, D. (1995). A dialogue: Culture, language, and race. Harvard Educational Review, 65(3), 377-402.

Gaudelli, W. (2016). Global citizenship education: Everyday transcendence. New York, NY: Routledge.

Giroux, H. A. (2020). On critical pedagogy. London: Bloomsbury.

Giroux, H. A., \& Bosio, E. (2021). Critical pedagogy and global citizenship education. In E. Bosio (Ed.), Conversations on global citizenship education: Perspectives on research, teaching, and learning in higher education (pp. 1-10). New York, NY: Routledge.

Glaser, B., \& Strauss, A. (1967). The discovery of grounded theory: Strategies for qualitative research. London: Wiedenfeld and Nicholson.

Glaser, B. G. (1965). The constant comparative method of qualitative analysis. Social Problems, 12(4), 436-445.

Goren, H., \& Yemini, M. (2017). The global citizenship education gap: Teacher perceptions of the relationship between global citizenship education and students' socio-economic status. Teaching and Teacher Education, 67, 9-22.

Ho, L. C., et al. (2018). Conceptions of global citizenship education in East and Southeast Asia. In I. Davies (Ed.), The Palgrave handbook of global citizenship and education. London: Palgrave Macmillan.

International Christian University (2021). Global studies. https://www.icu.ac.jp/en/academics/under graduate/major/major29/.

Kim, T. (2016). Internationalisation and development in East Asian higher education: An introduction. Comparative Education, 52(1), 1-7. https://doi.org/10.1080/03050068.2016.1144309.

Lupinacci, J. (2017). Addressing 21st century challenges in education: An ecocritical conceptual framework toward an ecotistical leadership in education. Impacting Education: Journal on Transforming Professional Practice, 2(1), 20-27. https://doi.org/10.5195/ie.2017.31.

Lupinacci, J., \& Happel-Parkins, A. (2015). Recognize, resist, and reconstitute: An ecocritical framework in teacher education. The SoJo Journal: Educational Foundations and Social Justice Education, 1(1), 45-61.

Lupinacci, J., \& Happel-Parkins, A. (2016a). Ecocritical foundations: Toward social justice and sustainability. In J. Diem (Ed.), The social and cultural foundations of education: A reader (pp. 34-56). San Diego, CA: Cognella.

Lupinacci, J., \& Happel-Parkins, A. (2016b). (Un)learning anthropocentrism: An ecojustice education framework for teaching to resist human-supremacy in schools. In S. Rice \& A. Rud (Eds.), The educational significance of human and non-human animal interactions: Blurring the species line (pp. 13-30). New York, NY: Palgrave Macmillan.

Marginson, S. (1999). After globalization: Emerging politics of education. Journal of Education Policy, 14(1), 19-31.

Marshall, H. (2011). Instrumentalism, ideals and imaginaries: Theorising the contested space of global citizenship education in schools. Globalisation, Societies and Education, 9(3-4), 411-426. https:// doi.org/10.1080/14767724.2011.605325.

Martusewicz, R., \& Edmundson, J. (2005). Social foundations as pedagogies of responsibility and ecoethical commitment. In D. W. Butin (Ed.), Teaching social foundations of education: Contexts, theories, and issues (pp. 71-92). Mahwah, NJ: Lawrence Erlbaum Associates. 
Mayo, P. (2019). Higher education in a globalising world. Manchester: Manchester University Press.

Merriam, S. B., \& Grenier, R. S. (Eds.) (2019). Qualitative research in practice: Examples for discussion and analysis. San Francisco, CA: Jossey-Bass.

Mignolo, W. (2000a). Local histories/global designs: Coloniality, subaltern knowledges, and border thinking. Princeton, NJ: Princeton University Press.

Mignolo, W. (2000b). The many faces of cosmo-polis: Border thinking and critical cosmopolitanism. Public Culture, 12(3), 721-748.

Misiaszek, G. W. (2015). Ecopedagogy and citizenship in the age of globalisation: Connections between environmental and global citizenship education to save the planet. European Journal of Education, 50(3), 280-292. https://doi.org/10.1111/ejed.12138.

Moon, R. J., \& Koo, J. W. (2011). Global citizenship and human rights: A longitudinal analysis of social studies and ethics textbooks in the Republic of Korea. Comparative Education Review, 55, 574599. https://doi.org/10.1086/660796.

Nitta, K. A. (2019). The politics of developing global human resources in Japan. Globalisation, societies and education, 17(3), 339-352. https://doi.org/10.1080/14767724.2018.1558046.

O'Connor, L., \& Faas, D. (2012). The impact of migration on national identity in a globalized world: A comparison of civic education curricula in England, France and Ireland. Irish Educational Studies, 31(1), 51-66. https://doi.org/10.1080/03323315.2011.579479.

Pashby, K., \& Andreotti, V. (2016). Ethical internationalisation in higher education: Interfaces with international development and sustainability. Environmental Education Research, 22(6), 771-787.

Pashby, K., da Costa, M., Stein, S., \& Andreotti, V. (2020). A meta-review of typologies of global citizenship education. Comparative Education, 56(2), 144-164. https://doi.org/10.1080/03050068. 2020.1723352.

Rapoport, A. (2010). We cannot teach what we don't know: Indiana teachers talk about global citizenship education. Education, Citizenship and Social Justice, 5(3), 179-190. https://doi.org/10.1177/ 1746197910382256.

Rizvi, F. (2007). Internationalization of curriculum: A critical perspective. In M. Hayden, J. Levy, \& J. Thompson (Eds.), The Sage handbook of research in international education (pp. 390-403). London: Sage Publications.

Rubin, H. J., \& Rubin, I. S. (2005). Qualitative interviewing. London: Sage Publications.

Schweisfurth, M. (2006). Education for global citizenship: Teacher agency and curricular structure in Ontario schools. Educational Review, 58, 41-50. https://doi.org/10.1080/00131910500352648.

Sophia University. (2021). Graduate program in global studies. https://www.sophia.ac.jp/eng/program/ graduate_p/gpgs/index.html.

Tarozzi, M., \& Inguaggiato, C. (2018). Implementing global citizenship education in EU primary schools: The role of government ministries. International Journal of Development Education and Global Learning, 10(1), 21-38. https://doi.org/10.18546/IJDEGL.10.1.03.

Torres, C. A. (2017). Theoretical and empirical foundations of critical global citizenship education. New York, NY: Routledge. https://doi.org/10.4324/9781315452579.

Torres, C. A., \& Bosio, E. (2020a). Global citizenship education at the crossroads: Globalization, global commons, common good, and critical consciousness. Prospects, 48, 99-113. https://doi.org/10. 1007/s11125-019-09458-w.

Torres, C. A., \& Bosio, E. (2020b). Critical reflections on the notion of global citizenship education. A dialogue with Carlos Alberto Torres in relation to higher education in the United States. Encyclopaideia, 24(56), 107-117. https://doi.org/10.6092/issn.1825-8670/10742.

UNESCO (2015). Global citizenship education: Topics and learning objectives. Paris: UNESCO.

University of Tokyo (2021). Global leadership program. http://www.glp.u-tokyo.ac.jp/en/glp/.

Weintraub, L., Phillips, P. C., Smith, S., Godfrey, D., Vesna, V., Rosenthal, A., et al. (2006). Forum: Eco-tistical art. Art Journal, 65(1), 54-81.

Yonezawa, Y. (2017). Internationalization management in Japanese universities: The effects of institutional structures and cultures. Journal of Studies in International Education, 21, 375-390. https:// doi.org/10.1177/1028315317706412.

Young, M. (2003). Durkheim, Vygotsky and the curriculum of the future. London Review of Education, 1(2), 100-119.

Publisher's Note Springer Nature remains neutral with regard to jurisdictional claims in published maps and institutional affiliations. 
Emiliano Bosio is an educator, author, and public intellectual. Currently, he teaches at Toyo University in Japan. He is the editor of Conversations on Global Citizenship Education (Routledge) and a research committee member at the Center for Global Nonkilling (CGNK) in the United States. Professor Bosio is also a contributor to the Academic Network on Global Education and Learning (ANGEL), a UK-based network established in close cooperation between the Global Education Network of Europe (GENE) and the Development Education Research Center (DERC) at the University College London Institute of Education. 